\title{
Formation Mechanism and Properties of Foam-Structured ZnO Films Prepared Using Catalyst-Free Carbothermal Method
}

\author{
Seok Cheol Choi $\mathbb{D}^{1},{ }^{1}$ Hong Tak Kim $\mathbb{D}^{D},{ }^{2}$ Taehun Jang $\mathbb{D}^{2},{ }^{2}$ and Sang Ho Sohn $\mathbb{D}^{2}$ \\ ${ }^{1}$ Department of Process Development, LG Electronics, Gumi 39247, Republic of Korea \\ ${ }^{2}$ Department of Physics, Kyungpook National University, Daegu 41566, Republic of Korea \\ Correspondence should be addressed to Sang Ho Sohn; shsohn@knu.ac.kr
}

Received 2 May 2019; Accepted 14 June 2019; Published 8 September 2019

Academic Editor: Miguel A. Correa-Duarte

Copyright (c) 2019 Seok Cheol Choi et al. This is an open access article distributed under the Creative Commons Attribution License, which permits unrestricted use, distribution, and reproduction in any medium, provided the original work is properly cited.

\begin{abstract}
Foam-structured $\mathrm{ZnO}$ films were formed on $c$-axis $\mathrm{Al}_{2} \mathrm{O}_{3}$ substrates by using a catalyst-free carbothermal method. The morphological properties of the films strongly depended on their substrate position in the reactor, implying that the quantity of $\mathrm{Zn}$ vapor transported played a crucial role in determining the film structure. The formation mechanism of the films is proposed to be as follows: with increased transport of $\mathrm{Zn}$ vapor, vaporized $\mathrm{Zn}$ elements transformed into liquid $\mathrm{Zn}$ nanoparticles, and the liquid $\mathrm{Zn}$ elements on the rods promoted the new nucleation of $\mathrm{ZnO}$ nanorods. The repeated growth of $\mathrm{ZnO}$ rods at the nucleation sites led to the foam-like structure. The as-formed foam-structured $\mathrm{ZnO}$ films exhibited the wurtzite crystal structure, and the atomic composition ratio of $\mathrm{Zn}$ to $\mathrm{O}$ was $1: 0.85$. The main photoluminescence emissions were centered at 3.3 and $2.5 \mathrm{eV}$, and they were attributed to band-to-band and defect-related transitions, respectively.
\end{abstract}

\section{Introduction}

Zinc oxide $(\mathrm{ZnO})$ has been receiving increasing attention owing to its promising properties, such as a bandgap that is direct and wide $(\approx 3.4 \mathrm{eV})$, an exciton binding energy that is large $(\approx 60 \mathrm{meV})$, high transparency in the visible region, high stability against high-energy radiation, and ease of etching in both acid and base media [1-5]. In particular, $\mathrm{ZnO}$ nanostructures have been attracting considerable interest because of their peculiar properties. They have been grown using various techniques such as chemical vapor deposition (CVD), physical vapor deposition, and solution techniques [1-3, 6-9]. In particular, in CVD methods, vapor-liquid-solid (VLS) and vapor-solid (VS) processes have been used widely to produce $\mathrm{ZnO}$ nanorods (NRs) $[4,10-12]$. While the VLS process usually requires a metal catalyst layer, the VS process facilitates direct deposition by transporting the metal oxide vapor from a high temperature to a low temperature.

In the present study, we focused on the formation of foam-structured $\mathrm{ZnO}$ (FS- $\mathrm{ZnO}$ ) films, which are characterized by a network of $\mathrm{ZnO}$ NRs, on $c$-axis $\mathrm{Al}_{2} \mathrm{O}_{3}$ substrates in a one-step VLS process. Furthermore, the properties of the films were investigated. The VLS process includes the formation of $\mathrm{Zn}$ vapor in a carbothermal reaction, nucleation of liquid $\mathrm{Zn}$ nanoparticles on $\mathrm{ZnO} \mathrm{NRs}$, and formation of $\mathrm{ZnO}$ NRs in an oxidation process. In this paper, in addition to a description and discussion of the aforementioned study, we propose a formation mechanism for the FS- $\mathrm{ZnO}$ films.

\section{Materials and Methods}

FS-ZnO films were formed on $c$-axis $\mathrm{Al}_{2} \mathrm{O}_{3}$ substrates $(4 \mathrm{~cm} \times 4 \mathrm{~cm})$ by using a catalyst-free carbothermal method. A schematic of the experimental setup used for the preparation of the nanostructural $\mathrm{ZnO}$ films is shown in Figure 1. A mixture of $\mathrm{ZnO}$ (99.9\%, Sigma-Aldrich) and graphite (99.9\%, Sigma-Aldrich) powders with a molar ratio of 7:1 was used as the precursor for the film preparation. The precursor was placed at the center of the alumina boat, and the substrates were positioned on the left $(\mathrm{L})$ and right $(\mathrm{R})$ sides of the precursor as well as at its center. The substrates on the left and right were at a distance of approximately $4 \mathrm{~mm}$ from the precursor. Prior to the growth process, the reactor used 


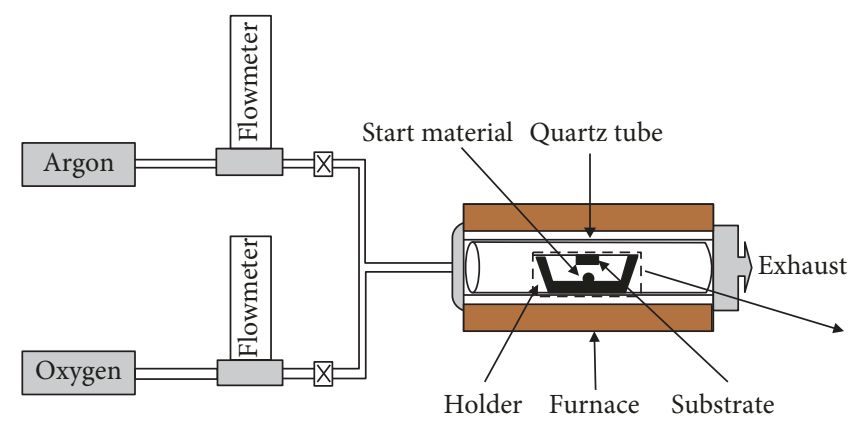

(a)

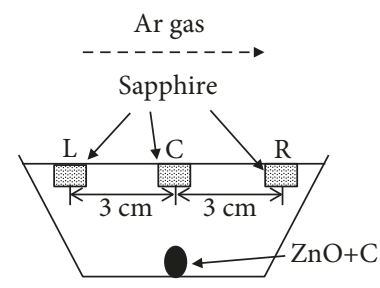

(b)

FIGURE 1: Schematic diagram of the (a) experimental setup for nanostructural $\mathrm{ZnO}$ film formations using a carbothermal reaction process and (b) substrate positions denoted by L, C, and R.

for the carbothermal reaction was purged with Ar gas for $1 \mathrm{~h}$ and subsequently heated up to $800^{\circ} \mathrm{C}$ at a rate of $5^{\circ} \mathrm{C} / \mathrm{min}$. After the desired temperature was attained, the growth time of $\mathrm{ZnO}$ films was $1 \mathrm{~h}$. During $\mathrm{ZnO}$ film growth, a mixture of $\mathrm{Ar}$ and $\mathrm{O}_{2}$ (Ar: 87\%; $\mathrm{O}_{2}: 13 \%$ ) was introduced in the reactor, and the partial pressure of each gas was controlled by flowmeters.

The morphological structure of the nanostructural $\mathrm{ZnO}$ films formed was characterized using a scanning electron microscope (SEM, Hitachi S-4800), and elemental analysis of the films was performed using an electron probe microanalyzer (EPMA, Shimadzu EPMA-1600) and energy dispersive X-ray spectroscopy (EDX, Hitachi S-4800). The structural properties of the nanostructural $\mathrm{ZnO}$ films were investigated using an X-ray diffractometer (XRD, PANalytical X'Pert $\mathrm{MPD}$ ), and the optoelectronic properties at room temperature were measured using photoluminescence (PL) spectroscopy (LabRAM HR, Sci-Tech Instruments). All the data was taken after more than five times of experiments.

\section{Results and Discussion}

Figure 2 shows the XRD spectra of nanostructural $\mathrm{ZnO}$ films formed at different substrate positions, which are indexed as $\mathrm{L}, \mathrm{C}$, and $\mathrm{R}$ zones. For all samples, diffraction peaks were mainly observed at $31.8^{\circ}, 34.4^{\circ}$, and $36.9^{\circ}$, corresponding to the (100), (002), and (101) diffraction planes of hexagonal $\mathrm{ZnO}$ with the wurtzite structure (JCPDS Card No. 01089-0510). The degree of preferred orientation for the films is indicated by the texture coefficient (TC), which is given by $[4,13]$

$$
T C(h k l)=\frac{I(h k l) / I_{0}(h k l)}{1 / n \sum_{n=1}^{n} I(h k l) / I_{0}(h k l)},
$$

where $I(h k l)$ and $I_{0}(h k l)$ are the measured and standard intensities of the $(h k l)$ peak, and $n$ is the number of diffraction peaks. The calculated TC values for the (002) diffraction peak for the as-deposited nanostructural $\mathrm{ZnO}$ films formed in the $\mathrm{L}, \mathrm{C}$, and $\mathrm{R}$ zones were $65 \%, 23 \%$, and $29 \%$, respectively. These values implied that the nanostructural $\mathrm{ZnO}$ films grown in the $\mathrm{L}$ zone showed a strong preferred orientation in the $c$-axis direction, while those

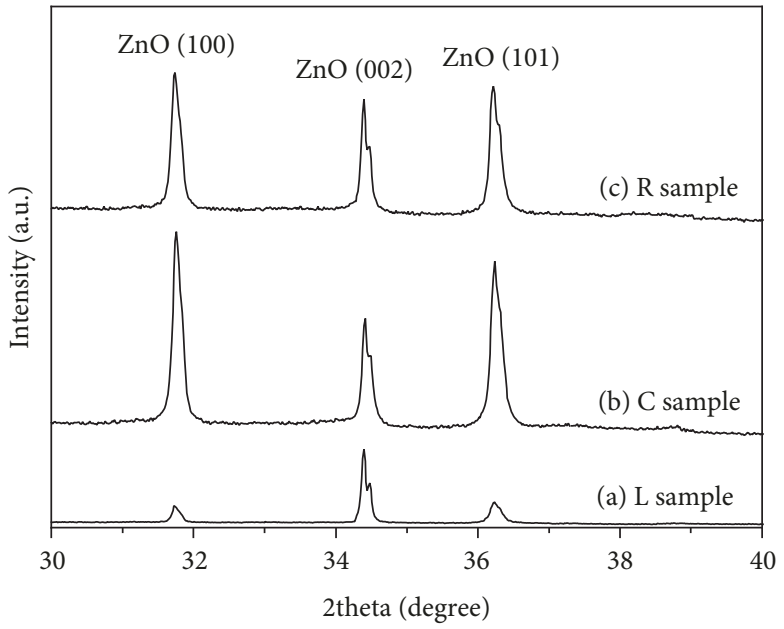

FIGURE 2: X-ray diffraction patterns of the nanostructural $\mathrm{ZnO}$ films formed in the $\mathrm{L}, \mathrm{C}$, and $\mathrm{R}$ zones.

prepared in the $\mathrm{C}$ and $\mathrm{R}$ zones did not exhibit any preferred orientation.

Figure 3 shows SEM images of nanostructural $\mathrm{ZnO}$ films formed in the $\mathrm{L}, \mathrm{C}$, and $\mathrm{R}$ zones. It is noteworthy that the sample grown in the L zone (Figure 3(a)) exhibits a hexagonal NR structure, whereas the samples prepared in the $\mathrm{C}$ and R zones (Figures $3(\mathrm{a})$ and $3(\mathrm{~d})$ ) show a network structure and foam-like structure, respectively.

Figure 4 shows a schematic of the growth mechanism of nanostructural $\mathrm{ZnO}$ films during their synthesis on sapphire substrates positioned at the left, center, and right side on top of the alumina boat. Ar and $\mathrm{O}$ gases are flowing from the left side toward the right side at the top of the boat. The structural differences between the $\mathrm{ZnO}$ films formed at different sample positions can be explained on the basis of the quantity of vaporized $\mathrm{Zn}$ elements transported. The transport of $\mathrm{Zn}$ vapor from the $\mathrm{L}$ zone to the $\mathrm{R}$ zone gradually increased, and it was accompanied by the flow of the $\mathrm{Ar}-\mathrm{O}_{2}$ gas mixture from the $\mathrm{L}$ zone to the $\mathrm{R}$ zone. In the $\mathrm{L}$ zone, the surface reaction on the substrate was important because of the transport of small $\mathrm{Zn}$ vapor in the $\mathrm{L}$ zone. The high surface energy of the $\mathrm{Al}_{2} \mathrm{O}_{3}$ substrate for $\mathrm{ZnO}$ formation lowered the 


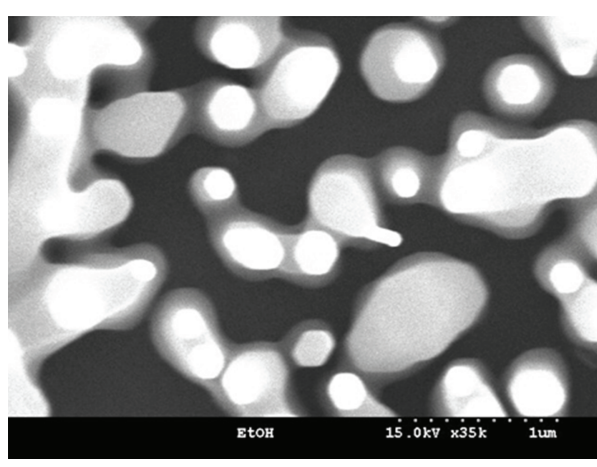

(a)

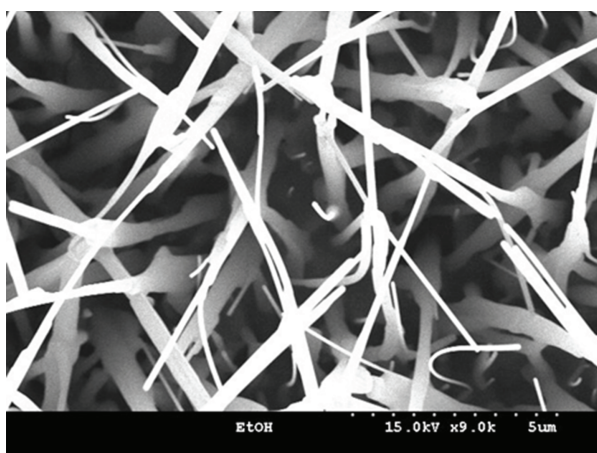

(c)

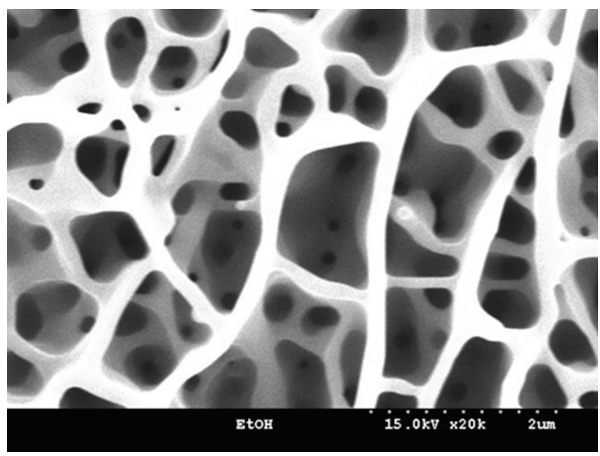

(e)

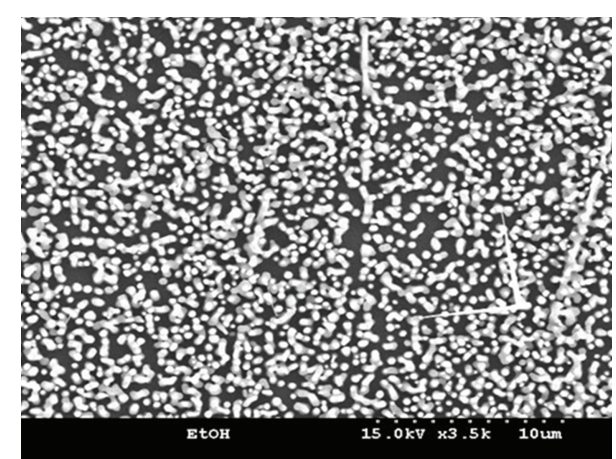

(b)

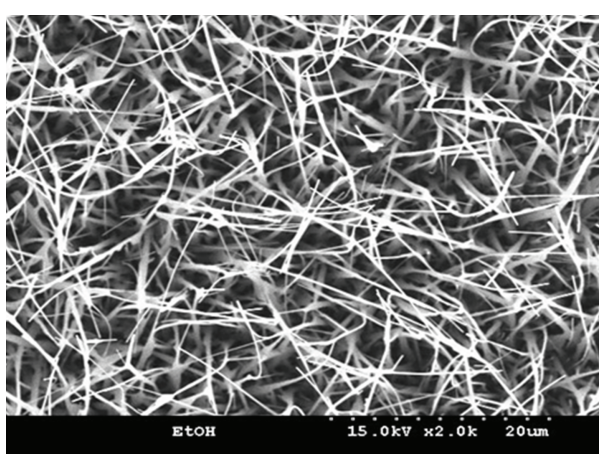

(d)

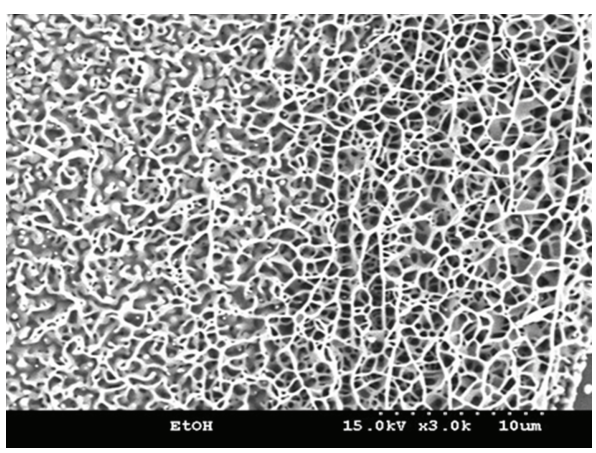

(f)

FIgURE 3: SEM images of nanostructural $\mathrm{ZnO}$ films formed in the $\mathrm{L}, \mathrm{C}$, and $\mathrm{R}$ zones. (a) and (b) show samples grown in the $\mathrm{L}$ zone. The two figures show the same samples but on different scales. Similarly, (c) and (d) show the same samples grown in the C zone, and (e) and (f) depict identical samples prepared in the $\mathrm{R}$ zone.

nucleation density of $\mathrm{ZnO}$ on the substrate, rendering the lateral growth of $\mathrm{ZnO}$ difficult. Consequently, the growth of $\mathrm{ZnO}$ on the substrate was in the $z$-axis direction rather than lateral, resulting in a hexagonal NR structure. In the $\mathrm{C}$ zone, the direction of NR growth was random and the NRs were partially connected to each other, resulting in a network structure. By contrast, in the R zone, the NRs were completely bridged to each other, resulting in a foam-like structure. In other words, vaporized $\mathrm{Zn}$ elements transformed into liquid $\mathrm{Zn}$ nanoparticles with the increased transport of $\mathrm{Zn}$ vapor. The liquid $\mathrm{Zn}$ elements on the NRs led to the new nucleation of $\mathrm{ZnO}$ NRs, and the repeated growth of $\mathrm{ZnO}$ NRs at nucleation sites led to a foam-like structure. The main chemical reactions leading to nanostructural $\mathrm{ZnO}$ film formation at the temperature considered in this study can be summarized as follows [14]:

$$
\begin{array}{r}
\mathrm{ZnO}(\mathrm{s})+\mathrm{C}(\mathrm{s}) \longrightarrow \mathrm{Z}(\mathrm{g})+\mathrm{CO}(\mathrm{g}) \\
2 \mathrm{Zn}(\mathrm{g})+\mathrm{O}_{2}(\mathrm{~g}) \longrightarrow 2 \mathrm{ZnO}(\mathrm{s}) \\
\mathrm{Zn}(\mathrm{g})+\mathrm{Zn}(\mathrm{l}) \text { on } \mathrm{ZnO}(\mathrm{s}) \longrightarrow{ }^{\mathrm{O}_{2}} \mathrm{ZnO}(\mathrm{s})
\end{array}
$$

Equation (2) represents the reduction process of $\mathrm{ZnO}$ in the carbothermal reaction, equation (3) describes $\mathrm{ZnO}$ formation in the reaction between the vaporized $\mathrm{Zn}$ element and $\mathrm{O}_{2}$ gas, and equation (4) represents NR formation by additional nucleation of the liquid $\mathrm{Zn}$ particles on $\mathrm{ZnO}$ NRs. 


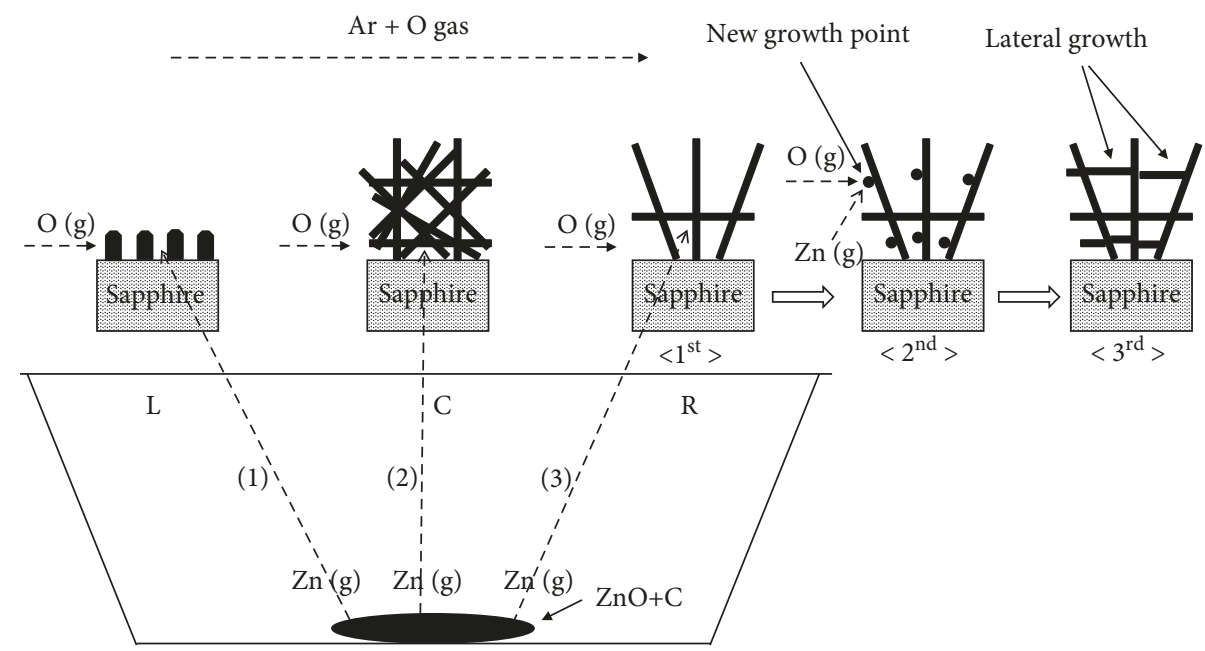

FIGURE 4: Schematic of the growth mechanism of nanostructural $\mathrm{ZnO}$ films at different substrate positions.

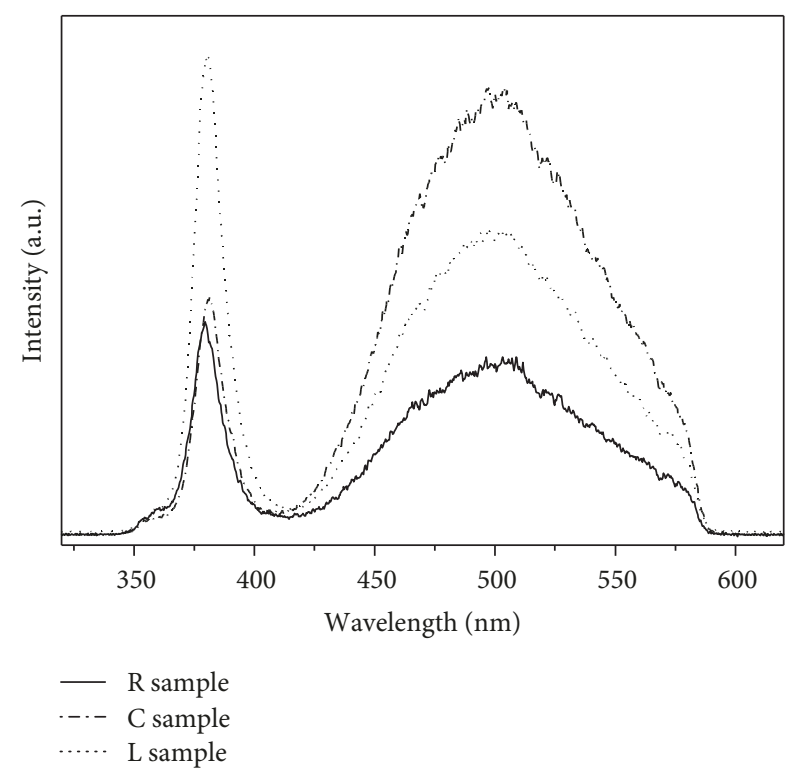

FIGURE 5: PL spectra of nanostructural $\mathrm{ZnO}$ films grown at $\mathrm{L}, \mathrm{C}$, and $\mathrm{R}$ zones.

Figure 5 shows PL spectra of nanostructural $\mathrm{ZnO}$ films grown at L, C, and R zones. As illustrated in Figure 5, the emission peaks in the spectrum were mainly observed at $380 \mathrm{~nm}(3.3 \mathrm{eV})$ and $500 \mathrm{~nm}(2.5 \mathrm{eV})$ for all samples. UV peaks centered at a wavelength of $380 \mathrm{~nm}\left(\mathrm{Peak}_{380}\right)$ were attributed to the band-to-band transition, and the visible peaks centered at $500 \mathrm{~nm}\left(\mathrm{Peak}_{500}\right)$ originated from the defect-related transitions [1,5]. The calculated values of $\mathrm{Peak}_{380} / \mathrm{Peak}_{500}$ ratio for as-grown nanostructural $\mathrm{ZnO}$ films formed at $\mathrm{L}, \mathrm{C}$, and $\mathrm{R}$ zones were $1.43,0.63$, and 1.22, respectively. Therefore, one can infer that the nanostructural $\mathrm{ZnO}$ films grown at the L zone have a relatively strong UV emission, probably due to a strong preferred orientation toward the $c$-axis, compared to the nanostructural $\mathrm{ZnO}$ films formed at the $\mathrm{C}$ and $\mathrm{R}$ zones exhibiting a weak preferred orientation as argued by TC values in Figure 2. The surface area of the foam-like structure increased dramatically, unlike other nanostructural $\mathrm{ZnO}$ films. Furthermore, the atomic ratio of $\mathrm{Zn}$ to $\mathrm{O}$ in the films was $1: 0.85$, and this was confirmed by the EPMA and EDX. Therefore, it is strongly suggested that the defect-related transitions around $500 \mathrm{~nm}$ were mainly caused by a surface defect and an oxygen vacancy. Thus, in FS-ZnO films, oxygen-deficient and surface-derived defects are strongly related to the visible emission of the PL spectrum of the films. Even though we have no experimental data at present, the defect-related peaks are expected to lessen by a heat treatment of samples in the oxygen atmosphere.

\section{Conclusions}

Foam-structured $\mathrm{ZnO}$ (FS- $\mathrm{ZnO}$ ) films were formed on $c$-axis $\mathrm{Al}_{2} \mathrm{O}_{3}$ substrates by using a catalyst-free carbothermal method. The as-formed films showed the wurtzite crystal structure, and the atomic composition ratio of $\mathrm{Zn}$ to $\mathrm{O}$ was approximately $1: 0.85$. Photoluminescence emissions centered at 3.3 and $2.5 \mathrm{eV}$ were attributed to band-to-band and defect-related transitions, respectively. The morphological properties of the nanostructural $\mathrm{ZnO}$ films strongly depended on their substrate positions in the reactor, implying that the quantity of $\mathrm{Zn}$ vapor transported played a crucial role in determining the film structure. Differences in the morphological structures of the nanostructural $\mathrm{ZnO}$ films could be explained on the basis of the quantity of vaporized $\mathrm{Zn}$ elements transported. The transport of $\mathrm{Zn}$ vapor gradually increased from the $\mathrm{L}$ zone to the $\mathrm{R}$ zone, and this was followed by the flow of $\mathrm{Ar}-\mathrm{O}_{2}$ gas mixture from the $\mathrm{L}$ zone to the $\mathrm{R}$ zone. We propose the following formation mechanism for the FS- ZnO films: with increased transport of $\mathrm{Zn}$ vapor, vaporized $\mathrm{Zn}$ elements transformed into liquid $\mathrm{Zn}$ nanoparticles. The liquid $\mathrm{Zn}$ elements on the rods promoted the new nucleation of $\mathrm{ZnO}$ rods, and the repeated growth of $\mathrm{ZnO}$ rods at the nucleation sites led to a foam-like structure. 


\section{Data Availability}

All the data of this manuscript used to support the findings of this study are available from the corresponding author upon request. Anyone who has questions about the results of the study could contact the authors freely.

\section{Conflicts of Interest}

The author(s) declare(s) that they have no conflicts of interest.

\section{Acknowledgments}

This research was supported by Basic Science Research Program through the National Research Foundation of Korea (NRF) funded by the Ministry of Education (NRF-2019R1I1A3A01041101).

\section{References}

[1] Ü. Özgür, Y. I. Alivov, C. Liu et al., "A comprehensive review of $\mathrm{ZnO}$ materials and devices," Journal of Applied Physics, vol. 98, no. 4, article 041301, 2005.

[2] H. Morkoç and Ü. Özgür, Zinc Oxide: Fundamentals, Materials and Device Technology, John Wiley \& Sons, 2008.

[3] K. Ellmer, A. Klein, and B. Rech, Transparent Conductive Zinc Oxide: Basics and Applications in Thin Film Solar Cells, Springer Science \& Business Media, 2007.

[4] H. T. Kim, S. Y. Lee, and Y. S. Sohn, "Formation mechanism and properties of nanorod-structured $\mathrm{ZnO}$ films prepared by pyrolysis of Zn acetate films," Vacuum, vol. 155, pp. 403407, 2018.

[5] H. T. Kim, S. Y. Lee, and C. Park, "Controls of surface morphology on sol-gel derived $\mathrm{ZnO}$ films under isothermal treatment conditions," Vacuum, vol. 143, pp. 312-315, 2017.

[6] K. C. Pradel, W. Wu, Y. Zhou, X. Wen, Y. Ding, and Z. L. Wang, "Piezotronic effect in solution-grown p-type $\mathrm{ZnO}$ nanowires and films," Nano Letters, vol. 13, no. 6, pp. 26472653, 2013.

[7] R. Kumar, O. Al-Dossary, G. Kumar, and A. Umar, "Zinc oxide nanostructures for $\mathrm{NO}_{2}$ gas-sensor applications: a review," Nano-Micro Letters, vol. 7, no. 2, pp. 97-120, 2015.

[8] Z. L. Wang, "Nanostructures of zinc oxide," Materials Today, vol. 7, no. 6, pp. 26-33, 2004.

[9] K. J. Chen, F. Y. Hung, S. J. Chang, S. J. Young, and Z. S. Hu, "Effects of crystallization on the optical properties of $\mathrm{ZnO}$ nano-pillar thin films by sol-gel method," Current Applied Physics, vol. 11, no. 5, pp. 1243-1248, 2011.

[10] M. H. Huang, S. Mao, H. Feick et al., "Room-temperature ultraviolet nanowire nanolasers," Science, vol. 292, no. 5523, pp. 1897-1899, 2001.

[11] Z. W. Pan, Z. R. Dai, and Z. L. Wang, "Nanobelts of semiconducting oxides," Science, vol. 291, no. 5510, pp. 1947-1949, 2001.

[12] C. C. Lin and Y. Y. Li, "Synthesis of $\mathrm{ZnO}$ nanowires by thermal decomposition of zinc acetate dihydrate," Materials Chemistry and Physics, vol. 113, no. 1, pp. 334-337, 2009.
[13] H. T. Kim, J. Y. Park, and C. Park, "Effects of nitrogen flow rate on titanium nitride films deposition by DC facing target sputtering method," Korean Journal of Chemical Engineering, vol. 29, no. 5, pp. 676-679, 2012.

[14] D. Das and P. Mondal, "Photoluminescence phenomena prevailing in $\mathrm{c}$-axis oriented intrinsic $\mathrm{ZnO}$ thin films prepared by RF magnetron sputtering," RSC Advances, vol. 4, no. 67, pp. 35735-35743, 2014. 


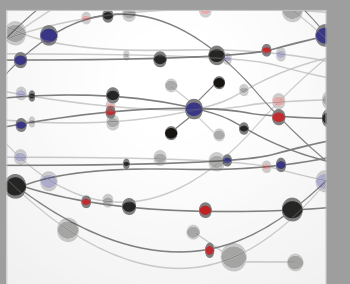

The Scientific World Journal
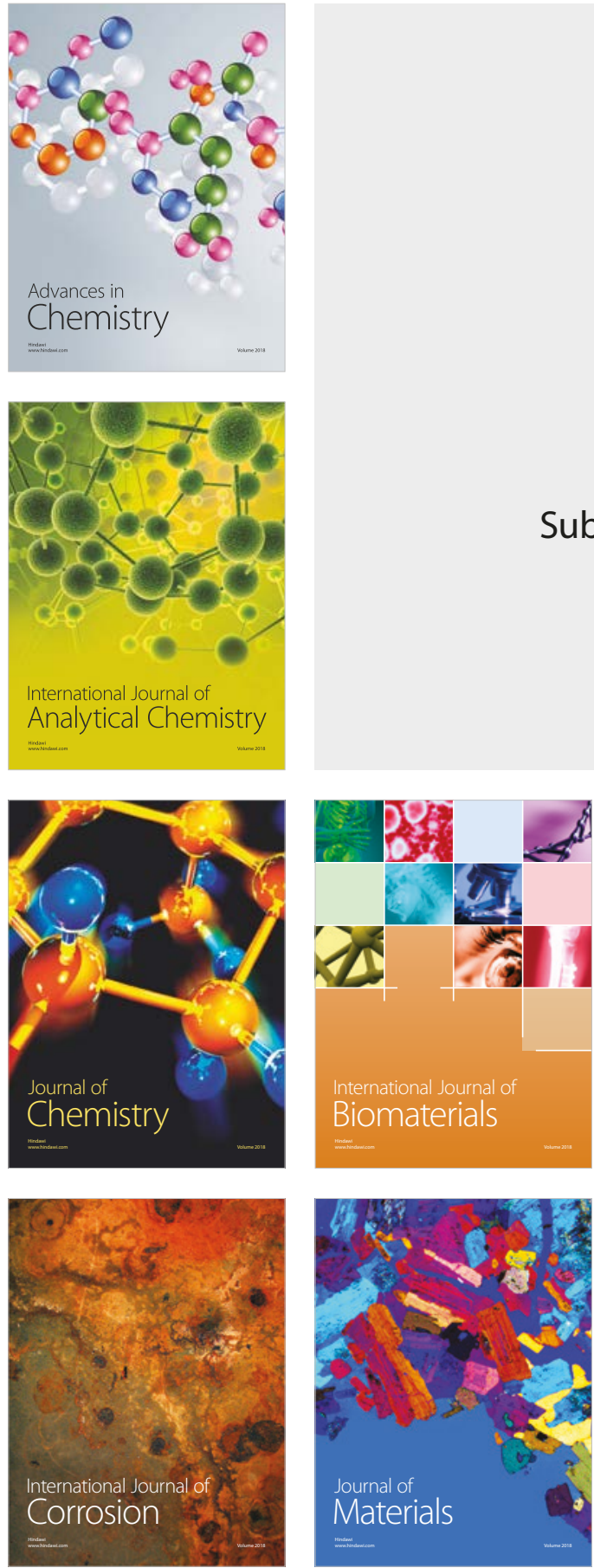

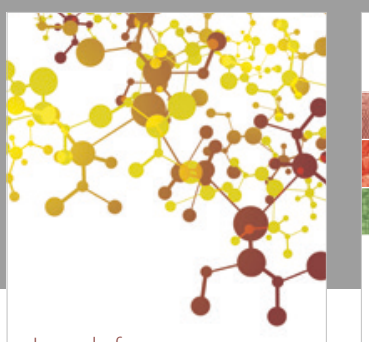

Journal of

Applied Chemistry
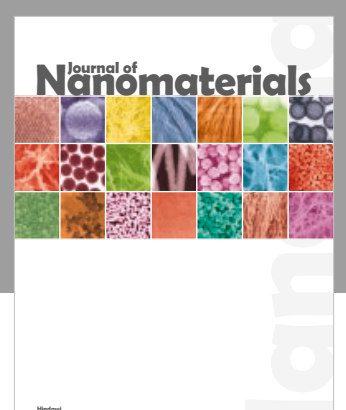

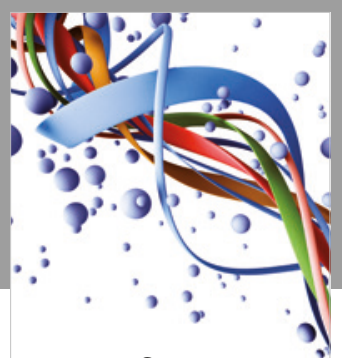

Scientifica

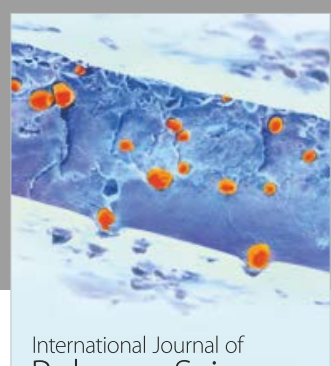

Polymer Science

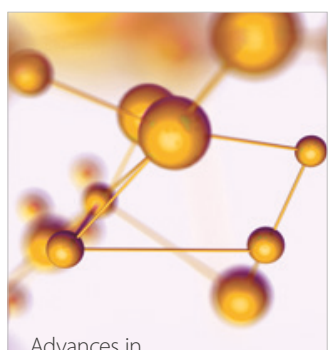

Physical Chemistry
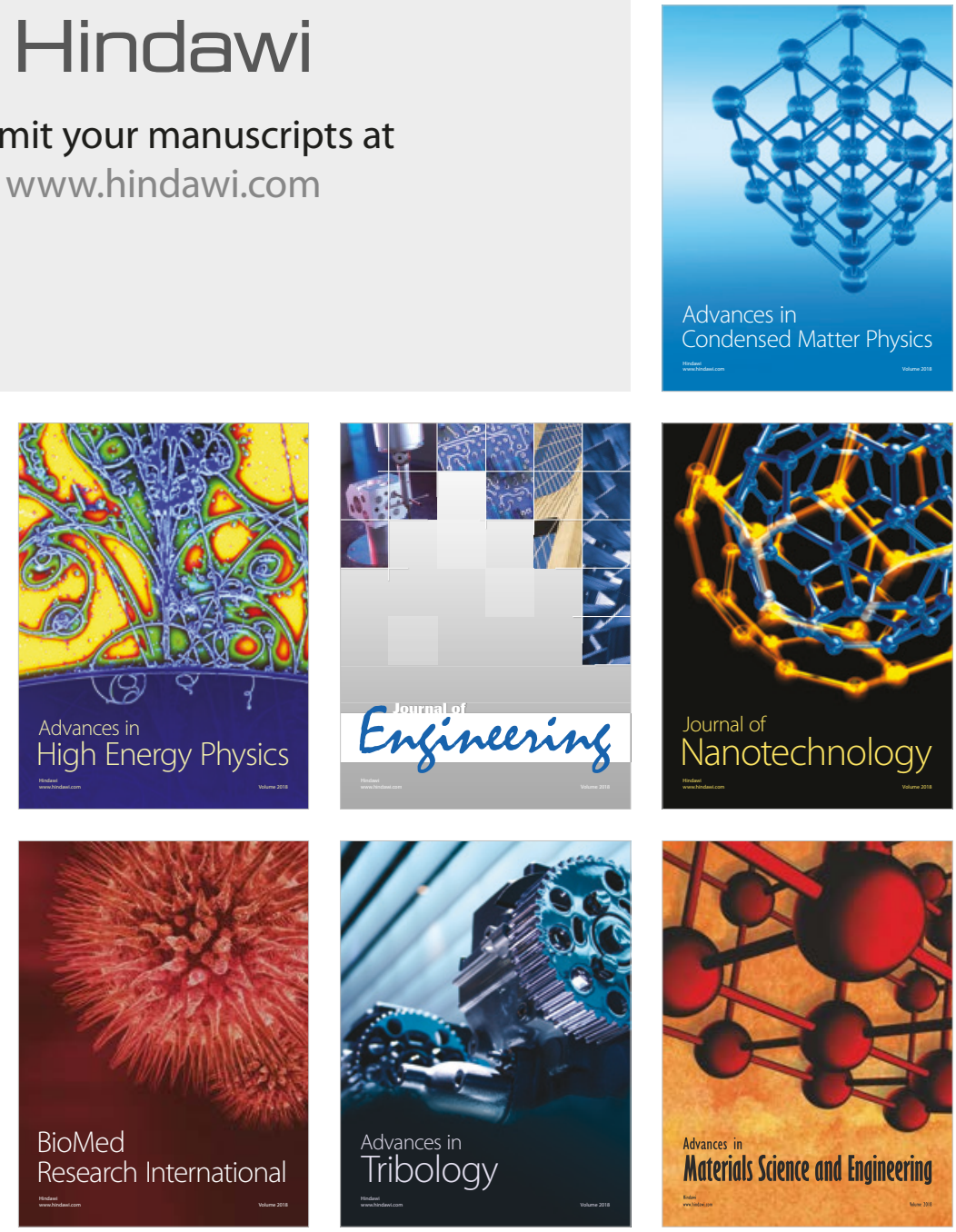